Disclosure of Interest: None declared

DOI: 10.1136/annrheumdis-2017-eular.2082

\section{AB0528 PATIENT ACTIVATION AND THE FACTORS AFFECTING IT IN PRIMARY SJÖGREN'S SYNDROME}

S.T. Souter ${ }^{1}$, B. Hargreaves ${ }^{2}$, K.L. Hackett ${ }^{3}$, W.-F. $\mathrm{Ng}^{3} .{ }^{1}$ Newcastle University; ${ }^{2}$ Freeman Hospital; ${ }^{3}$ Institute of Cellular Medicine \& NIHR Newcastle Biomedical Science Research Centre, Newcastle upon Tyne, United Kingdom

Background: Increased patient activation has been associated with reduced costs of treatment ${ }^{1}$ and improved patient outcomes ${ }^{2}$. The effect of primary Sjögren's syndrome (pSS) on patient activation however has not been established.

Objectives: This study aims to identify how activated patients with pSS are, and to ascertain whether factors such as ESSPRI score, EULAR dryness score and self-reported quality of life influence this.

Methods: Patient activation in 170 pSS patients was assessed using the 13-item Patient Activation Measure (PAM-13). A PAM-13 score from 0-100 was obtained using the PAM-13 Scoring Spreadsheet, which also gave a corresponding activation level ranging from 1-4. Descriptive statistics of the PAM-13 scores was performed, and frequency analysis of the corresponding activation level. Demographic, clinical and self-reported measures such as age, gender, ESSPRI score and EQ5D-3L score were linked to each patients' PAM-13 scores. Spearman's correlation analysis was performed to assess the relationship between the continuous variables and PAM-13 score, and Fisher's exact test was used to assess the relationship between activation level and the categorical variables.

Results: The mean PAM-13 score of the 170 patients studied was 59.5 (SD 13.5). $17.6 \%$ of patients were in level 1 of activation, $26.5 \%$ in level $2,40.0 \%$ in level 3 , and $15.9 \%$ in level 4 . The mean age of the sample was 59.6 (SD 13.1), and $83.5 \%$ were female.

EQ5D-3L score had the strongest correlation with increased PAM score $\left(r_{s}\right.$ $0.405, p 0.000$ ). Increasing self-reported pain in the ESSPRI questionnaire was correlated with a decreasing PAM score $\left(r_{s}-0.355, p 0.000\right)$, as was increasing ESSPRI score $\left(r_{s}-0.337, p\right.$ 0.000). Increasing abnormal fatigue $\left(r_{s}-0.189, p\right.$ $0.016)$ and EULAR dryness $\left(r_{s}-0.190, p 0.013\right)$ score were only weakly correlated with a decrease in PAM-13 score. Decreases in patients self-reported mobility ( $p$ 0.000 ), self-care ( $p$ 0.002), and ability to perform daily activities ( $p$ 0.018) were also associated with differences in activation score.

Conclusions: Factors such as a patients self-reported health and pain have a moderate correlation with activation in pSS patients, while dryness and fatigue are only weakly correlated with changes in activation. This should be considered in the future when devising treatment plans and clinical trials.

\section{References:}

[1] Hibbard JH, Greene J, Overton V. Patients With Lower Activation Associated With Higher Costs; Delivery Systems Should Know Their Patients' 'Scores'. Health Affairs. 2013;32(2):216-222.

[2] Hibbard JH, Greene J, Shi Y, Mittler J, Scanlon D. Taking the Long View: How Well Do Patient Activation Scores Predict Outcomes Four Years Later? Medical Care Research and Review. 2015;72(3):324-337.

Disclosure of Interest: None declared

DOI: 10.1136/annrheumdis-2017-eular.6933

\section{AB0529 ROLE OF THE ANTI-R052 AND RO60 ANTIBODIES QUANTIFICATION IN PATIENTS WITH SYSTEMIC LUPUS ERYTHEMATOSUS}

S. Heredia ${ }^{1}$, M. Martinez-Morillo ${ }^{1}$, A. Riveros ${ }^{1}$, L. Gifre ${ }^{1}$, A. Teniente-Serra ${ }^{2}$, B. Quirant ${ }^{2}$, S. Holgado ${ }^{1}$, L. Mateo ${ }^{1}$, A. Prior ${ }^{1}$, Y. Garcia $^{1}$, J. Camins ${ }^{1}$,

E. Martínez-Cáceres ${ }^{2}$, A. Olivé ${ }^{1} .{ }^{1}$ Rheumatology; ${ }^{2}$ Immunology, Hospital Universitari Germans Trias i Pujol, Badalona, Spain

Background: Anti-Ro antibodies (Ab) are especially directed against two antigens, Ro52 and Ro60, with different structure and function. Studies in systemic lupus erythematosus (SLE) have been described a relationship between the presence of anti-Ro Ab and dry syndrome, subacute cutaneous lupus, myocardial involvement or minor renal involvement. However, studies about the clinical usefulness of determining the 2 specificities of anti-Ro Ab in SLE are not conclusive. It seems that anti-Ro52 could be associated with joint involvement and lung disease, while anti-Ro60 could be related to late-onset SLE. In this paper we evaluate the clinical usefullness of anti-Ro52 and Ro60 Ab chemiluminescence quantification in patients with SLE.

Objectives: To analyze the presence of anti-Ro52 and Ro60 Ab in a cohort of patients with SLE and evaluate its correlation with clinical, analytical and immunological parameters.

Methods: 152 patients with SLE (according to the SLICC criteria 2013) attended in an university hospital were included. Qualitative immunoblot analysis of anti-Ro $A b$ was performed on all of them; those with positive values were also assessed by a chemiluminescence quantification of anti-Ro52 and Ro60 Ac (normality $<19.9 \mathrm{CU}$ ). Other LES specific Ab were also analyzed by immunoblot, indirect immunofluorescence and ELISA. Clinical variables (age, oral ulcers, alopecia, synovitis, serositis, antiphospholipid syndrome (APS), Sjögren's syndrome, cutaneous, neurological and renal involvement), analytical (complement, cytopenia and coombs test) and activity and damage index of SLE (SLEDAI and SLICC) were also evaluated. The study was approved by the Clinical Research Ethics Committee of the center, and all patients signed informed consent.

Results: $91 \%$ (138) were women with a mean age of $46 \pm 12$ years (range, $20-75$ ) and an average SLE evolution of $12 \pm 7$ years (range, $1-40) .32 \%(49 / 138)$ of the patients had anti-Ro positive determination by immunoblot: 36 were anti-Ro52 positive (mean value $696 \pm 726 \mathrm{CU}$ ) and 48 anti-Ro60 positive (mean value $504 \pm 696 \mathrm{CU}$ ) by chemiluminescence. Only one anti-Ro52 positive patient was anti-Ro60 negative. $10.5 \%$ had late-onset SLE. The mean SLEDAI was $1.84 \pm 2.48$ while the SLICC was $0.32 \pm 0.7$, with a mean anti(ds)DNA Ac values about $207.87 \pm 357.15 \mathrm{IU} / \mathrm{ml}$. 37.5\% had hypocomplementemia. Anti-Ro positive patients by immunoblot had a higher value of anti(ds)DNA compared to the patients without Ro positive values and patients with both positivity by chemiluminescence had lower prevalence of APS, however the quantitative values of anti-Ro52 and anti-Ro60 were not related with clinical, analytical or immunological parameters. Conclusions: $32 \%$ of patients in the cohort were anti-Ro positive being mostly anti-Ro60 positive. The presence of anti-Ro Ab was associated with higher value of antiDNAds and lower prevalence of APS. However, the quantitative values of anti-Ro52 and anti-Ro60 Ab by chemiluminescence were not related to the different parameters analyzed in the study. These results indicate the need to assess the quantification of anti-Ro Ab in a larger cohort of patients with SLE.

Disclosure of Interest: None declared

DOI: 10.1136/annrheumdis-2017-eular.5057

\section{AB0530 PREVALANCE OF OSTEONECROSIS OF BONE IN PATIENTS OF SLE IN A NEWLY ESTABLISHED RHEUMATOLOGY CLINIC IN CENTRAL INDIA}

S. Malviya ${ }^{1}$, N. Gupta ${ }^{2}$, R. Gupta ${ }^{3}$. ${ }^{1}$ Department of Rheumatology, Indore, India, Medanta Superspeciality Hospital; ${ }^{2}$ Department of Anaesthesia, SAIMS, Indore, Indore; ${ }^{3}$ Department of Rheumatology, Indore, India, MEDANTA Medicity, Gurugram, India

Background: Osteonecrosis (OCN) is a well recognized complication of SLE. The prevalence rate of AVN in SLE ranges from $8-25 \%$ in various studies. It is always debatable if corticosteroids or disease itself causes OCN. Although long term corticosteroids use can cause OCN, but in few cases and studies it has shown disease itself can be the causative event.

Objectives: To study the prevalance of Osteonecrosis of bone among patients of SLE attending the newly established Rheumatology clinic over 2 years time.

Methods: All the patients of SLE with OCN attending the newly established Rheumatology clinic of the town were included in the study.OCN was diagnosed on the basis of MRI after screening with X-ray.Serological data collected. Routine investigations done were collected. Details of patients were included in a set proforma and details noted in the same.

Results: Among 180 patients of SLE were included in the study. Among those, 9 patients $(5 \%)$ were diagnosed with OCN. Seven patients of OCN had been on steroids but 2 patients never received any drugs, both were male. All the patients were AN A positive (Homegenous pattern in 6 and Speckled in 3), Anti-ds-DNA was positive in 7 and Anti-Smith in 2. Most common site of OCN was Femur head $(n=6)$, Lower femoral condyles in 2 patinets of OCN and head of Talus in 1. Anti-phospholipid antibodies were found in 3 patients.

Conclusions: Osteonecrosis was found in $5 \%$ of patients of SLE. Most of the patients had active disease with OCN occurred very early during the course of disease. This suggest $\mathrm{OCN}$ can be seen due to disease itself as 2 patients never received any drugs. Most common antibodies associated was anti ds-DNA antibody. So among patients of SLE with hip or pain in joints/bone not explaining active arthritis, OCN should be ruled out.

\section{References:}

[1] Lam G.K.W, Petri M. Assessment of Systemic Lupus Erythematosus. Clin Exp Rheumatol 2005;23 (Suppl. 39): S120-132.

[2] Mont MA, Glueck CJ, Pacheco IH, Wang P, Hungerford DS, Petri M. Risk factors for osteonecrosis in systemic lupus erythematosus. J Rheumatol 1997;24:654-62.

[3] Petri M. Musculoskeletal complications of systemic lupus erythematosus in the Hopkins Lupus Cohort: an update. Arthritis Care Res 1995;8:137-45.

[4] Dubois EL, Cozen L. Avascular (aseptic) bone necrosis associated with systemic lupus erythematosus. JAMA 1960;174:966-71.

[5] Harrington KD, Murray WR, Kountz SL, Belzer FD. Avascular necrosis of bone after renal transplantation. J Bone Joint Surg Am 1971;53:203-15.

[6] Murray WR. Hip problems associated with organ transplants. Clin Orthop 1973:90:57-69.

[7] Heimann WG, Freiberger RH. Avascular necrosis of the femoral and humeral heads after high dosage corticosteroid therapy. N Engl J Med 1960;263:672-5.

[8] Abeles M, Urman JD, Rothfield NF. Aseptic necrosis of bone in systemic lupus erythematosus. Relationship to corticosteroid therapy. Arch Intern Med 1978;138:750-4.

Acknowledgements: Dr Arvind Rawal: Orthopaedician.

Dr Mallika Kwatra- Pathologist

Dr Sandeep Shrivastava- Director

Disclosure of Interest: None declared

DOI: 10.1136/annrheumdis-2017-eular.4634 